OPEN ACCESS

Edited by:

Gianluca Lista,

Ospedale dei Bambini Vittore

Buzzi, Italy

Reviewed by: Mats Blennow,

Karolinska University

Hospital, Sweden

Jiang-Qin Liu,

Shanghai First Maternity and Infant

Hospital, China

Camilla Gizzi,

Sandro Pertini Hospital, Italy

*Correspondence:

Misrak Tadesse

mtadess1@jhmi.edu

Specialty section:

This article was submitted to

Neonatology,

a section of the journal

Frontiers in Pediatrics

Received: 16 September 2021 Accepted: 02 November 2021 Published: 25 November 2021

Citation:

Tadesse M, Hally S, Rent S, Platt PL,

Eusterbrock T, Gezahegn W, Kifle T,

Kukora S and Pollack LD (2021) Effect of a Low-Dose/High-Frequency

Training in Introducing a Nurse-Led Neonatal Advanced Life Support Service in a Referral Hospital in

Ethiopia. Front. Pediatr. 9:777978. doi: 10.3389/fped.2021.777978

\section{Effect of a}

Low-Dose/High-Frequency Training in Introducing a Nurse-Led Neonatal Advanced Life Support Service in a Referral Hospital in Ethiopia

\author{
Misrak Tadesse ${ }^{1,2 *}$, Suzanne Hally ${ }^{1,3,4}$, Sharla Rent ${ }^{5}$, Phillip L. Platt ${ }^{1,6}$, \\ Thomas Eusterbrock $^{1,7}$, Wendmagegn Gezahegn ${ }^{8}$, Tsinat Kifle ${ }^{8}$, Stephanie Kukora ${ }^{5}$ and \\ Louis D. Pollack ${ }^{1,7}$ \\ ${ }^{1}$ Wax \& Gold Inc., Amarillo, TX, United States, ${ }^{2}$ Division of Neonatology, Department of Pediatrics, Johns Hopkins University \\ School of Medicine, Baltimore, MD, United States, ${ }^{3}$ Division of Neonatology, Department of Pediatrics, Massachusetts \\ General Hospital, Boston, MA, United States, ${ }^{4}$ School of Nursing, Endicott College, Boston, MA, United States, ${ }^{5}$ Division of \\ Neonatology, Department of Pediatrics, University of Michigan, Ann Arbor, MI, United States, ${ }^{6}$ Pediatrix Medical Group, \\ Department of Neonatology, Baptist St Anthony's Hospital, Amarillo, TX, United States, ${ }^{7}$ Division of Neonatology, Alta Bates \\ Summit Medical Center, Berkeley, CA, United States, ${ }^{8}$ Saint Paul's Hospital Millennium Medical College, Addis \\ Ababa, Ethiopia
}

Background and Objective: In Ethiopia, birth asphyxia causes 30\% of all neonatal deaths and $11-31 \%$ of deaths among neonates delivered in healthcare facilities that have breathing difficulty at birth. This study aimed to examine the impact of low-dose, high-frequency (LDHF) training for introducing a nurse-led neonatal advanced life support (NALS) service in a tertiary care hospital in Ethiopia.

Methods: Through a retrospective cohort study, a total of 12,001 neonates born post-implementation of the NALS service (between June 2017 and March 2019) were compared to 2,066 neonates born before its implementation (between June 2016 and September 2016). Based on when the neonates were born, they were divided into six groups (groups A to F). All deliveries occurred in the inpatient Labor and Delivery Unit (LDU) at St. Paul's Hospital Millennium Medical College. The number of neonatal deaths in the LDU, neonatal intensive care unit (NICU) admission rate, and proportion of neonates with normal axillary temperature $\left(36.5-37.5^{\circ} \mathrm{C}\right)$ within the first hour of life were evaluated. Data were analyzed using the $\chi^{2}$ test, and $p$-values $<0.05$ were considered statistically significant. Following the implementation of the NALS service, semi-structured interviews with key stakeholders were conducted to evaluate their perception of the service; the interviews were recorded, transcribed, and coded for thematic analysis.

Results: There was a decrease in the proportion of neonates who died in the LDU (from 3.5 to 1\%) during the immediate post-implementation period, followed by a sustained decrease over the study period $(\rho<0.001)$. The change in the NICU admission rate (from 22.8 to $21.2 \%$ ) was insignificant $(p=0.6)$ during this initial period. However, this was followed by a significant sustained decrease (7.8\% in group $E$ and $9.8 \%$ in group $F, p<0.001)$. The proportion of newborns with normal axillary temperature improved 
from $46.2 \%$ during the initial post-implementation period to $87.8 \%(p<0.01)$; this proportion further increased to $99.8 \%$. The program was perceived positively by NALS team members, NICU care providers, and hospital administrators.

Conclusion: In resource-limited settings, LDHF training for neonatal resuscitation improves the neonatal resuscitation skills and management of delivery room attendants.

Keywords: neonatal resuscitation, global health, neonatal mortality, Ethiopia, delivery room, low-and middleincome countries, low-dose high-frequency training, quality improvement

\section{INTRODUCTION}

Neonatal mortality, defined as death that occurs within the first 28 days of life, accounts for $47 \%$ of global deaths of children under the age of 5 years (1). Most neonatal deaths occur due to preventable conditions, such as birth asphyxia. Approximately one-third of such deaths occur within the first day of life, and $\sim 3$-quarters of such deaths occur within the first week of life (1). Neonatal deaths in Sub-Saharan African (SSA) countries account for $37 \%$ of under-five mortality (2). In 2019, Ethiopia ranked second in Africa and fourth in the world among the top 10 countries with the highest number of neonatal deaths, with an estimated 99,000 neonatal deaths $(1,3)$. Between 2011 and 2019, significant strides toward the improvement of maternal healthcare have been made in Ethiopia. With these improvements, the proportion of women receiving antenatal care increased from 19 to $43 \%$, and the proportion of births that occurred in health facilities increased from 10 to $48 \%$ (4). However, the neonatal mortality rate (NMR) remains high at 33 deaths per 1,000 live births, a minimal decrease was observed from 37 deaths per 1,000 live births in 2011 (4).

The urgency associated with neonatal mortality has increased since even newborns who benefit from being born in healthcare facilities are not faring well (5-7). In Ethiopia, birth asphyxia is the cause of $\sim 30 \%$ of all neonatal deaths and $11-31 \%$ of neonatal deaths among those who were delivered in healthcare facilities and required assistance for breathing difficulties (8-10).

There are several factors behind the high NMR, including the fact that only an estimated $50 \%$ of births are attended by skilled providers, and there is a shortage of providers skilled in the provision of neonatal resuscitation and postnatal care $(4,9,11$, 12). In high-income countries, the standardization of training, knowledge, and skills for neonatal resuscitation has resulted in a significant decrease in neonatal mortality (13). Although neonatal outcomes in low- and middle-income countries (LMIC) could be improved through the implementation of such programs, progress in this regard has been hindered by challenges associated with the provision of supplies, education, and training (14). Only $15 \%$ of hospitals in SSA countries have the capability for basic neonatal resuscitation (15). The analysis from the 2016 national Emergency Obstetric and Newborn Care Survey in

Abbreviations: LDHF, low-dose, high-frequency; LDU, Labor and Delivery Unit; LMIC, low- and middle-income countries; NALS, neonatal advanced life support; NICU, neonatal intensive care unit; NMR, neonatal mortality rate; SPHMMC, St.Paul's Hospital Millennium Medical College; SSA, Sub-Saharan African; S.T.A.B.L.E, Sugar, Temperature, Airway, Lab work, and Emotional support.
Ethiopia is in line with this finding (12). Inadequately trained staff, missing equipment, poor skill retention, and poor staffing are some of the barriers to the availability of basic resuscitation capabilities (16).

While the low-dose, high-frequency (LDHF) training model has been endorsed to foster skill retention following initial training, building a sustainable capacity for the improvement of the quality of neonatal resuscitation in an LMIC setting will ultimately depend on the development and implementation of programs involving the education and mentoring of clinicians for the creation of a train-the-trainer model (13, 17-19).

The neonatal advanced life support (NALS) program implemented at St. Paul's Hospital Millennium Medical College (SPHMMC) builds on the Helping Babies Survive programs designed by the American Academy of Pediatrics and includes advanced neonatal resuscitation, post-resuscitation care with respiratory and cardiovascular support, intra- and inter-facility transportation of sick newborns, data collection, and qualityimprovement methodologies. As described by Jhpiego, an LDHF training model was utilized that focused on short and frequent didactic sessions that helped build competency through simulation and case-based learning. It was team-focused and facility-based, and learners had ongoing exposure to content after initial training followed by intermittent supportive mentorship and performance evaluation spaced over 12 months (19).

\section{MATERIALS AND METHODS}

\section{Design}

This retrospective cohort study was conducted in the inpatient Labor and Delivery Unit (LDU) at SPHMMC, a regional tertiary referral hospital in $<$ city $>$ Addis $A b a b a</$ city $>$, Ethiopia, that serves a catchment population of $\sim 5$ million individuals. Annually, more than 12,000 deliveries are performed at SPHMMC. Approximately, two-thirds of the newborns are delivered in the inpatient LDU while the remaining are delivered in the outpatient LDU.

\section{Intervention}

In 2015, SPHMMC invited Wax and Gold, Inc., a USbased 501(c)3 non-profit organization working in Ethiopia in education and capacity building to improve newborn healthcare, to establish a collaborative partnership for the design and implementation of a NALS service. After interviews with key stakeholders and the performance of a needs assessment, a 
12-month longitudinal curriculum including didactic lectures, simulation scenarios, mentored clinical practicum, case reviews, and quality-improvement training was developed to train a dedicated team of nurses to attend all high-risk deliveries and provide newborn stabilization and resuscitation. The NALS team was selected from existing hospital staff, and it included 10 neonatal intensive care unit (NICU) nurses and one midwife, all of whom had Bachelor of Science degrees and at least 2 years of experience with bedside patient care.

The training curriculum was developed using existing educational platforms, including the American Academy of Pediatrics' Helping Babies Survive and Neonatal Resuscitation programs, the Sugar, Temperature, Airway, Blood Pressure, Lab work, and Emotional support (S.T.A.B.L.E) program, and the comprehensive competency-based orientation program designed by the Association of Women's Health, Obstetric, and Neonatal Nurses (Table 1) (20-23). As part of the interventions, a plastic wrap was used for thermoregulation, and T-piece resuscitators were used to provide positive pressure ventilation and continuous positive airway pressure. The training involved $110 \mathrm{~h}$ of didactic presentations and simulation-based training followed by $120 \mathrm{~h}$ of hands-on practicum in the LDU with case review, $20 \mathrm{~h}$ of supplemental lectures and interactive learning regarding quality-improvement methodologies and data management, and 6 additional months of intermittent bedside clinical mentorship. Experts in neonatal care and resuscitation from the US and Ethiopia led the didactic and hands-on portions of this training. Concurrently, a standard data collection form was developed (Figure 1) and validated for user-friendliness, workflow, and acceptance. Using MySQL Workbench (Oracle Corporation, Austin, TX, USA), the Information Technology Department of SPHMMC built and maintained a computerized database that was obtained using the data-collection form (24). The NALS service was initially rolled out in the inpatient LDU in December 2016 and was fully implemented in June 2017 (Figure 2).

\section{Data Collection and Analysis}

Three outcomes were studied: neonatal death in the inpatient LDU, rate of admission to the NICU from the inpatient LDU, and the proportions of neonates with normal axillary temperature $\left(36.5-37.5^{\circ} \mathrm{C}\right)$ within $1 \mathrm{~h}$ of life. After the implementation of the NALS program, five separate groups (groups B to F) consisting of all newborns from the inpatient LDU were identified and compared to a group of neonates (group A) born before the implementation of the program (between June 4, 2016 and September 17, 2016) from the same LDU. Data were entered in real-time on a paper form and then transferred to an electronic database maintained in a password-protected desktop computer in the LDU. Before the introduction of the NALS program, neonatal temperatures were not recorded.

Initial post-implementation data were collected from June 4, 2017 to September 17, 2017 (group B). There was a subsequent 2-month pause for the validation of data entry of group B and additional training. The second data entry period extended from November 15, 2017 to May 24, 2018 (group C); again, this was followed by validation. Starting from July 1, 2018, data

TABLE 1 | NALS curriculum developed to train a dedicated staff to provide newborn stabilization and resuscitation.

\begin{tabular}{ll}
\hline NALS Curriculum & Hours in \\
Training
\end{tabular}

Maternal, fetal and newborn pathophysiology

Helping babies survive

S.T.A.B.L.E

(S, Sugar and Safe care

$\mathrm{T}$, Temperature

A, Airway

$\mathrm{B}$, Blood pressure

L, Lab

E, Emotional support)

Neonatal resuscitation program

One to one practicum in the delivery room improvement
Didactic teaching developed by WAG, focusing on a thorough understanding of normal and pathologic maternal, fetal, and newborn physiology.

Didactic and simulation training adapted from AAP Helping Babies Breathe (HBB): initial steps of neonatal resuscitation for care in The Golden Minute including drying, suctioning, stimulation, and positive pressure ventilation; Essential Care for Every Baby (ECEB): newborn care practices from delivery to hospital discharge; and Essential Care for Small Babies (ECSB): newborn care specialized for small and premature infants.

Didactic teaching adapted from

S.T.A.B.L.E. neonatal nursing education curriculum on topics of evaluation and management of newborns, including glucose monitoring and management, assessment of respiratory status and blood pressure, laboratory evaluation, and parental support.

Didactic and simulation training including low fidelity simulation scenarios based on the AAP evidence-based approach to neonatal resuscitation and team-based care of the newborn at delivery. This included advanced airway techniques including intubation, cardiopulmonary resuscitation (CPR) as

well as umbilical catheterization and administration of epinephrine.

Supervised ALS trained provider attendance of deliveries at SPHMMC by WAG volunteers (neonatologists, neonatal nurse practitioners, and neonatal nurses from the US and Canada) with continued hands-on training and mentoring.

Didactic teaching on outcome improvement through continuous analysis of practice performance and modification, as well as hands-on teaching on the topic of data collection using the developed form and electronic data entry.

.


Data Entry ID

Form Version 01.01.02

1. Patient ID: Mother's Name Date of Delivery

SPHMMC Data Collection

2. Organization

- ALS notfied before delvery

- Motemal History discussed with 08 team

- If high risk, ALS arrival prior to delivery (Exicolan) Tmeofirn (NWPM)

- Location of Delvery

- Equipment avalable and functioning

- Warm blanket
: Clastic vrap
: Rap
: Suction (oub or mechanical)
: Oxygen
: T-piece resusctator
: Appropriate size mask
- Ambu bag

3. Maternal Prenatal

- Age yrs/gravida / / Para AB / Living

- Prenatal Care (at least one antenatal care vist) _- 1) yes

- Mutiple gestrion

4. Maternal Intrapartum

- ROM $>18$ hours

- Temperature $>38^{\circ} \mathrm{C}$

- Antenatal antbiotics

M-MRE

- Antenatal magnesium

- Antenztal steroids

- If Vaginal Delivery

- IF C-section Delivery - Indication

- Meconium present

- AbruptionUterine npture

- Cord complication

- Anesthesia

$$
\text { - Epiduralspinal }
$$

- General

- Delayed cord olamping (>1 minute)

5. Newborn Delivery

- Gender

- Gestixional Age complesed weeks 1) by dxes

- Weight grams

- apgar

- Resuscitaion 1) spontaneous 2) foroeps 1) yes

$\begin{array}{lll}\text { 1) yes } & \text { 2) no } & \text { 9) unknown } \\ \text { 1) yes } & \text { 2) no } & \text { 9) unknown } \\ \text { 1) yes } & \text { 2) no } & \text { 9) unknown } \\ \text { 2) OPD } & \text { 3) OR } & \text { 9) unknown } \\ \text { 1) yes } & \text { 2) no } & \text { 9) unknown } \\ \text { 1) yes } & \text { 2) no } & \text { 9) unknown } \\ \text { 1) yes } & \text { 2) no } & \text { 9) unknown } \\ \text { 1) yes } & \text { 2) no } & \text { 9) unknown } \\ \text { 1) yes } & \text { 2) no } & \text { 9) unknown } \\ \text { 1) yes } & \text { 2) no } & \text { 9) unknown } \\ \text { 1) yes } & \text { 2) no } & \text { 9) unknown } \\ \text { 1) yes } & \text { 2) no } & \text { 9) unknown } \\ \text { 1) yes } & \text { 2) no } & \text { 9) unknown }\end{array}$

- Drying (incluoing plastic wrap and blanket) - Tactile stimulation

- Airway suctioning

- Supplemental oxygen CPAP PPV

Chest compressions

Tracheal intubation for resuscitation

- Medication (Adrenalin, Dextrose, NS)

1) yes

1) yes

1) yes

1) yes

1) yes

9) unknown

- Number of providers required for adequate resuscitation

- Temperature (LEFT axilary)

- Disposition of necrote: intial (before weight check)

1) elective

2) no

9) unknown

2) $n 0$

9) unknown

- Was the NICU notfied prior to NICU admission

- If admitted to the NICU temperature on arrival to the NCU

- Date and time of cisposion: Dxce:

1) fetal

2) no

9) unknown

2) no

9) unknown

2) no $\quad$ 9) uniknown

2) no 9) unknown

2) no $\quad$ 9) unknown

plastic vacuum 9) unknown

2) emergent 8) uniknown

$\begin{array}{lll}\text { 2) matemal } & \text { 9) uniknown }\end{array}$

$\begin{array}{lll}\text { 1) yes } & \text { 2) no } & \text { 9) unknown }\end{array}$

$\begin{array}{lll}\text { 1) yes } & \text { 2) no } & \text { 9) unknown }\end{array}$

$\begin{array}{lll}\text { 1) yes } & \text { 2) no } & \text { 9) unknown }\end{array}$

$\begin{array}{lll}\text { 1) yes } & \text { 2) no } & \text { 9) unknown }\end{array}$

$\begin{array}{lll}\text { 1) yes } & \text { 2) no } & \text { g) unknown }\end{array}$

$\begin{array}{lll}\text { 1) yes } & \text { 2) no } & \text { 9) unknown }\end{array}$

$\begin{array}{lll}\text { 1) yes } & \text { 2) no } & \text { 9) unknown }\end{array}$

1) female 2) male 3) ambiguous 9) unknown 2) by frst trimesser u's 3) by exam

conpleted by. Name:

Form (Etriogian) Tme (Ethiogion) Tme: (AWPM) 10 (AMPM) Signature 20 minutes (if $<7$ ) $(t<\pi)$

9) unkinown $\begin{array}{lll}\text { 1) yes } & \text { 2) no } & \text { 9) unknown }\end{array}$ $\begin{array}{lll}\text { 1) yes } & \text { 2) no } & \text { 9) unknown }\end{array}$ $\begin{array}{lll}\text { 1) yes } & \text { 2) no } & \text { 9) unknown }\end{array}$ $\begin{array}{lll}\text { 1) yes } & \text { 2) no } & \text { 9) unknown }\end{array}$ $\begin{array}{lll}\text { 1) yes } & \text { 2) no } & \text { 9) unknown }\end{array}$ $\begin{array}{lll}\text { 1) yes } & \text { 2) no } & \text { 9) unknown }\end{array}$ $\begin{array}{lll}\text { 1) yes } & \text { 2) no } & \text { 9) unknown }\end{array}$ $\begin{array}{lll}\text { 1) yes } & \text { 2) no } & \text { 9) unknown }\end{array}$

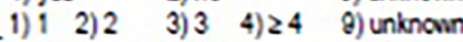
$\begin{array}{lll}\text { 1) yes } & 2 \text { ) no } & \text { 9) uniknown }\end{array}$ 15-60 mirutes (after stablization) 3) Died 9) Uniknown 


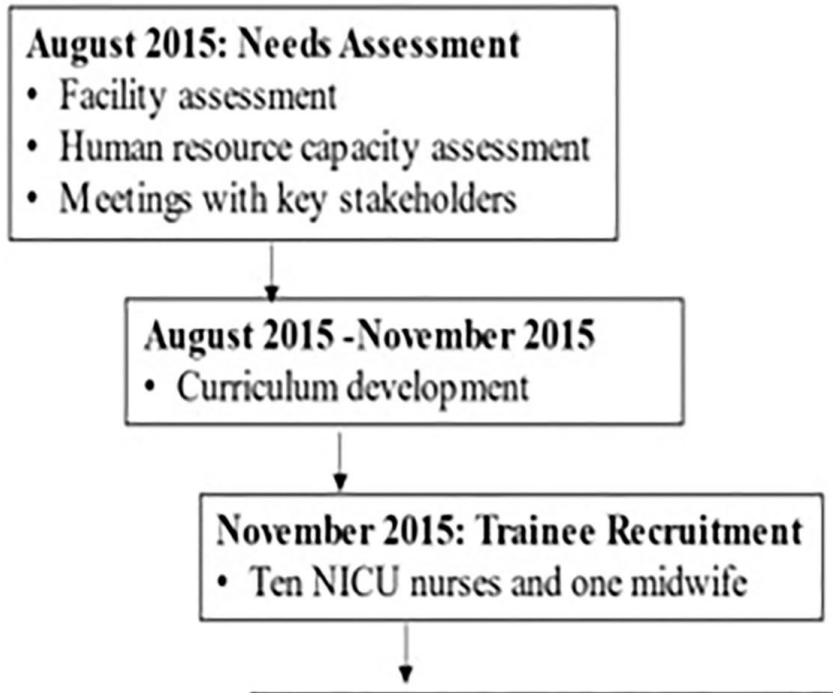

December 2015November 2016: Training and Certification

- Low-dose-high-frequency leaming-110 hours of didactic lectures and 120 hours of handson practicum

December 2016. June 2017: Senice Implementation

- On the job mentoring

- Database development

- Clinical service implementation

June 2016-March 2019: Data collection and analysis

Quality measures studied:

- Neonatal death in the inpatient LDU

- Rate of NICU admission from the inpatient LDU

- Rate of normal axillary temperature by one hour of life

measure. Data were analyzed using the $\chi^{2}$ test, and $p<0.05$ was considered statistically significant.

Additionally, a qualitative analysis of the NALS program was performed by an independent study team that identified staff perceptions of the feasibility, effectiveness, and acceptability of the NALS program. Semi-structured interviews were conducted at SPHMMC in January 2018. Twenty individuals, including NALS team members, NICU nurses, physicians, and hospital administrators, were interviewed to assess the perceived impact of the introduction of the NALS program on neonatal outcomes. For this purpose, medical staff who were willing to participate were identified ahead of time by the lead SPHMMC research partner. Participants were then recruited based on a convenience sample on the day of the interview. Interviews were conducted in English with the assistance of a local interpreter when needed. All interviews were audio-recorded, transcribed verbatim, and subsequently underwent thematic analysis. This study was approved by the institutional review board and leadership of SPHMMC. No parental consent was required for this quality improvement initiative. Consent was obtained from the healthcare providers participating in the survey.

\section{RESULTS}

During the initial period of the analysis of data on group A (preimplementation) and groups B and C (post-implementation), the 
TABLE 2 | Birth rate and NICU admission rate before and during the initial two periods after implementation of the NALS service.

\begin{tabular}{|c|c|c|c|c|c|}
\hline Cohort & Dates & Deliveries $(n)$ & Deliveries per day, mean & NICU admission (\%) & NICU admissions per day, mean \\
\hline A & June 4, 2016-Sept 17, 2016 & 2,066 & 19.7 & $472(22.8 \%)$ & 4.5 \\
\hline$B$ & June 4, 2017-Sept 17, 2017 & 2,299 & 21.9 & $496(21.6 \%)$ & 4.7 \\
\hline C & Nov 15, 2017-May 24, 2018 & 4,269 & 17.1 & 445 (10.4\%) & 1.8 \\
\hline D & July 1, 2018-Sept. 30, 2018 & 1,239 & 13.6 & $106(8.6 \%)$ & 1.2 \\
\hline$E$ & Oct. 1, 2018-Dec. 31, 2018 & 1,205 & 13.2 & $94(7.8 \%)$ & 1.0 \\
\hline $\mathrm{F}$ & Jan 1, 2019-March 31, 2019 & 2,989 & 33.2 & $270(9.0 \%)$ & 3.0 \\
\hline
\end{tabular}

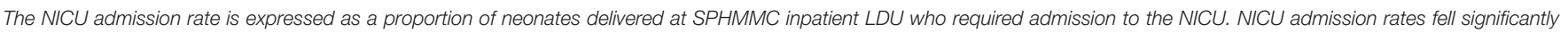
between Groups A and C $(p<0.001)$.

TABLE 3 | Neonatal death rate in the inpatient LDU before and after the implementation of the NALS service.

\begin{tabular}{llcc}
\hline Cohort & Dates & $\begin{array}{c}\text { Deliveries } \\
(\boldsymbol{n})\end{array}$ & $\begin{array}{c}\text { Neonatal death rate } \\
\text { in the inpatient LDU } \\
\boldsymbol{n}(\%)\end{array}$ \\
\hline A & June 4, 2016-Sept 17, 2016 & 2,066 & $73(3.53 \%)$ \\
B & June 4, 2017-Sept 17, 2017 & 2,299 & $22(0.96 \%)$ \\
C & Nov 15, 2017-May 24, 2018 & 4,269 & $14(0.33 \%)$ \\
D & July 1, 2018-Sept. 30, 2018 & 1,239 & $2(0.16 \%)$ \\
E & Oct. 1, 2018-Dec. 31, 2018 & 1,205 & $6(0.49 \%)$ \\
F & Jan 1, 2019-March 31, 2019 & 2,989 & $12(0.4 \%)$ \\
\hline
\end{tabular}

Mortality rate decreased significantly between groups $A$ and $C(p<0.001)$ and remained stable between groups $C-F(p=0.89)$.

number of deliveries remained stable, with a mean of 19.7, 21.9, and 17.1 deliveries per day in groups A, B, and C, respectively (Table 2). Concurrently, the rate of NICU admissions from the inpatient LDU decreased significantly from $22.8 \%$ in group A to $10.4 \%$ in group $\mathrm{C}(p<0.001)$. After the implementation of the NALS program, there was a decrease in the proportion of neonates who died (neonatal mortality) in the inpatient LDU; neonatal mortality in the inpatient LDU was $3.5,1.0$, and $0.3 \%$ in groups A, B, and C, respectively ( $p<0.001$ ) (Table 3; Figure 3). The NALS providers were not responsible for assigning the cause of death. Only the occurrence of death was recorded in the NALS database. The target axillary temperatures $\left(36.5-37.5^{\circ} \mathrm{C}\right)$ were achieved within the first h of life in $46.2 \%$ of the neonates in group $\mathrm{B}$ and $87.8 \%(p<0.01)$ of the neonates in group C (Table 4$)$.

Over the study period, in groups $\mathrm{D}$ and $\mathrm{E}$, the number of deliveries per day decreased to 13.6 and 13.2, respectively (Table 2). No specific reasons were identified for the decline in the number of births. There was a significant increase in the number of deliveries per day in group $\mathrm{F}$ to 33.2 , attributed to a process change implemented to consolidate all the deliveries into the inpatient LDU (Table 2).

During the same time, the decrease in the NICU admission rate observed in group $\mathrm{C}$ remained stable; among groups $\mathrm{D}, \mathrm{E}$, and F, the NICU admission rate ranged from 7.8 to $9 \%$ ( $p=$ 0.11) (Table 2; Figure 3). A sustained decrease in mortality was also observed among groups D, E, and F, ranging from $0.2-0.5 \%$ $(p=0.89)$ (Table 4; Figure 3). Likewise, there was a sustained improvement in the percentage of neonates who achieved target axillary temperatures within the first h of life; $99.8 \%$ of patients in group $\mathrm{G}$, the combined cohort representing groups $\mathrm{D}$ to $\mathrm{F}$, achieved axillary temperatures within the target temperature range (Table 4). There were no worsening of outcomes identified at any checkpoint that required a review of the NALS process.

In the subsequent qualitative analysis, the overall impact of the implementation of the NALS program on neonatal outcomes was evaluated. The responses of the NALS team members and those of the NICU care providers and hospital administrators were analyzed separately. The themes identified in NALS teammember interviews included the value of education and training, pride in work, and confidence in skills. Themes identified in the interviews of the NICU staff and hospital officials included praise for program outcomes, improvement in workflow, and desire for additional training opportunities. All interviewees were pleased with the progress in neonatal outcomes observed in SPHMMC following the implementation of the NALS service. Illustrative quotes from NALS team members have been included in Table 5, and quotes from the NICU providers and senior hospital administrators have been included in Table 6.

\section{DISCUSSION}

In this study, we quantified the improvement in immediate postnatal outcomes following the provision of education and skills training; the study findings demonstrated the feasibility of teaching and sustaining advanced neonatal-resuscitation skills to healthcare providers in an LMIC setting. SPHMMC is the only public hospital in Ethiopia with certified NALS providers responsible for all high-risk deliveries, and our study is the first one in Ethiopia to document that LDHF training with a curriculum developed using existing programs with proven effectivity, coupled with extensive, consistent, and repetitive theoretical and hands-on bedside training in similar clinicalpractice environments, is effective. This training program could serve as a model for the dissemination of neonatal-resuscitation skills in other healthcare institutions and hospitals in LMICs.

For the implementation of this training model, we relied on buy-in from key stakeholders to create an efficient and functional NALS program. Similar to almost all hospitals in Ethiopia, SPHMMC, despite being the largest delivery service in the country, did not have healthcare providers adequately trained 


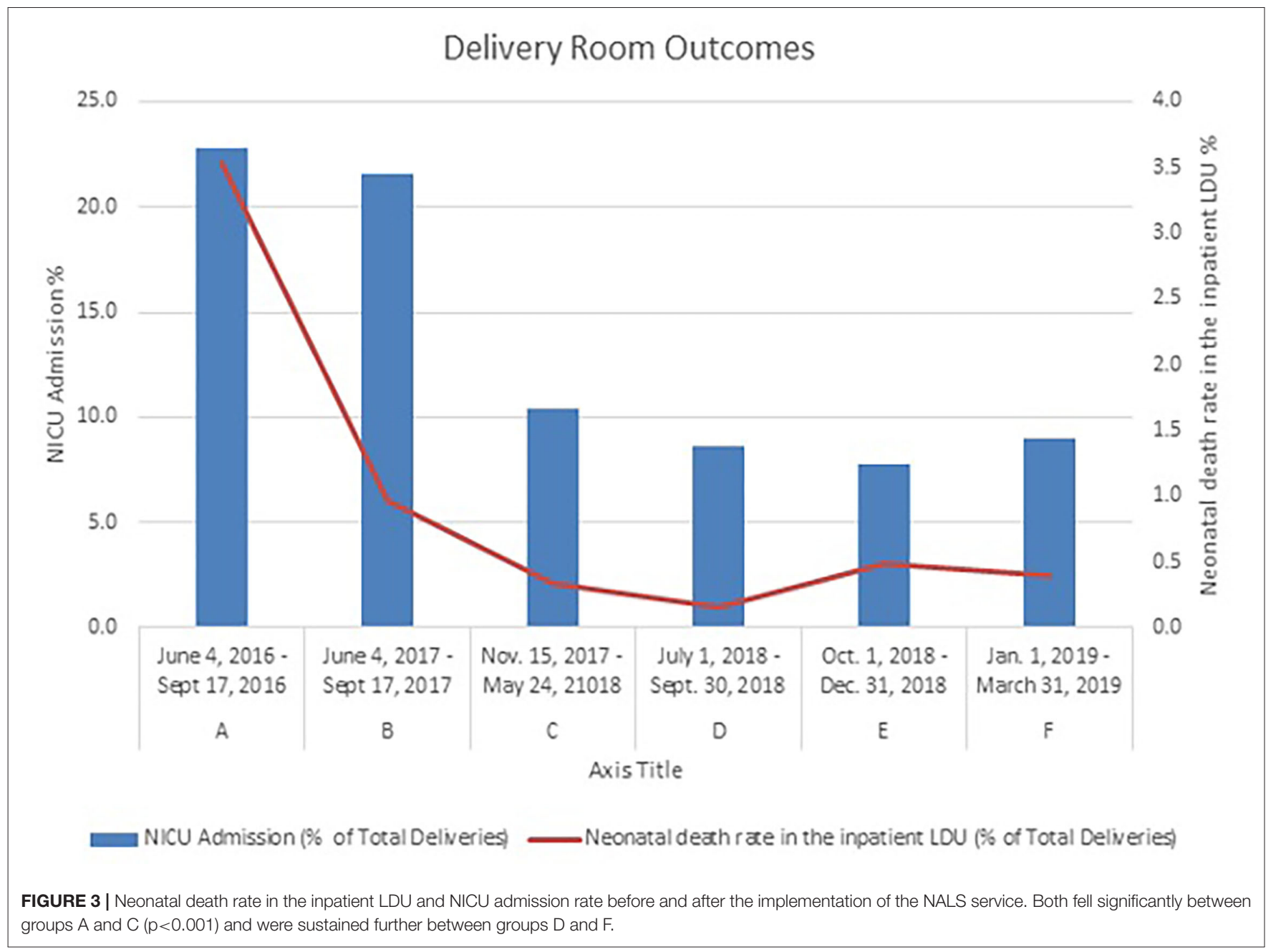

TABLE 4 | Rate of axillary temperature in the normal range $\left(36.5-37.5^{\circ} \mathrm{C}\right)$ after the implementation of the NALS service.

\begin{tabular}{llcc}
\hline Cohort & Dates & $\begin{array}{c}\text { Deliveries } \\
(\boldsymbol{n})\end{array}$ & $\begin{array}{c}\text { Axillary temperatures } \\
\text { between } \mathbf{3 6 . 5 - 3 7 . 5 ^ { \circ } \mathbf { C }} \\
\text { in the first h of life } \\
\text { (\%) }\end{array}$ \\
\hline A & June 4, 2016-Sept 17, 2016 & 2,066 & Not measured \\
B & June 4, 2016-Sept 17, 2017 & 2,299 & $1,062(46.2 \%)$ \\
C & Nov 15, 2017-May 24, 2018 & 4,269 & $3,748(87.8 \%)$ \\
G & July 1, 2018-March 31, 2019 & 5,433 & $5,420(99.8 \%)$ \\
\hline
\end{tabular}

No data were collected before the NALS implementation. Rates of normothermia improved significantly between Groups $B$ and $C(p<0.01)$. Group $G$ represents a composite of data collected following cohort $\mathrm{C}$.

in neonatal resuscitation. The administration of SPHMMC envisioned training and developing a NALS service in the delivery room. The engagement of stakeholders in pediatrics, obstetrics, nursing, and information technology was a crucial aspect of the collaboration and innovation required for the implementation and maintenance of this program.
In addition to the LDHF training strategy, the fact that the pace of the training was set according to that of the slowest learner, and the training was conducted in the same setting where the NALS team would eventually practice contributed significantly to the success of the project. The NALS team members were able to identify challenges in their practice environment and work on solutions. Intermittent mentoring in the inpatient LDU carried out by Wax and Gold physicians and nursing volunteers for the first 6 months following the implementation of the service helped the team reinforce their skills and build their confidence.

An additional feature of this NALS program was the emphasis on nurse-driven education and sustainability efforts. Job dissatisfaction leading to high attrition rates among nursing personnel is a major problem in the Ethiopian public healthcare system (25). Furthermore, inconsistent training in neonatal resuscitation among caregivers is a major contributor to persistently high neonatal mortality and morbidity rates in Ethiopian referral hospitals (26). The NALS training at SPHMMC has equipped these providers with the skills and knowledge required for them to be confident and satisfied with their abilities, resulting in a dramatic improvement in neonatal 
TABLE 5 | Quotes regarding the impact made by the Advanced Life Support (ALS) Team at St. Paul's Hospital.

\section{Major Themes with Representative Quotes from Neonatal ALS Team}

\section{Members}

\section{Value of NALS Education and Training}

"We were taught to take care of the babies very well. Resuscitate. We have enough equipment, manpower ... our team is equipped by materials and education. I think this is it. That is the reason for improvements in outcomes." -NALS Team Nurse

\section{Confidence in Skills}

"Our role is that we care for newborns if they need resuscitation. If the baby is meconium aspirated, or preterm, or struggling to breathe, and any other baby who needs our help we give it. We have received specialized training and skills training, so I believe we have made an impact. We have impacted outcomes and babies are surviving because they are receiving resuscitation." -NALS Team Nurse

"Outcomes are much improved. The change is from the way resuscitation is done. How to resuscitate the babies immediately, with a focus on the golden time of resuscitation. Immediately when the baby comes, if the baby cries already, we dry the baby and wrap with a dry towel and keep him warm. If he is not crying, we immediately see the airway ... whether it is clear or not. We clear the airway, wrap and stimulate the baby. If he is not crying, not improving still, will do MR SOPA. This ... after MR SOPA, most of the babies will cry and give a response. That is how we know we have done well." -NALS Team Nurse

\section{Pride in Work}

"At this hospital, there is a special team called the ALS team. In other hospitals the babies are handled with midwives. These midwives are giving newborn babies resuscitation, but it is not as good. But this training, ALS team training, gives us special resuscitation for newborn babies. This is good. It decreases neonatal mortality; especially immediate neonatal deaths have decreased. I think we can be proud of this change." -NALS Team Nurse

"I used to work in the NICU and would see babies referred from the obstetrical ward being hypothermic, hypoglycemic, not being resuscitated. We were the ones doing the resuscitation here. Since we can now get to them early and doing the resuscitation there, I feel really good." -NALS Team Nurse

Quotes were obtained during the qualitative interviews of NALS Team Members in January 2018.

mortality and morbidity immediately after birth. These objective outcome improvements have led the NALS team to be recognized as a vital element of neonatal care at SPHMMC.

The continued success of this model relies on the persistent utilization of neonatal resuscitation skills by trained providers and the eventual training of others by those clinicians. Members of the first NALS cohort who expressed a desire to teach others, in addition to demonstrating exceptional clinical skills were invited to take a leadership role in training the second cohort to develop a self-sustaining program with the support of the hospital leadership. Two classes of NALS providers have been certified to date.

Following the successful implementation of the NALS program at SPHMMC, leadership at SPHMMC and Wax and Gold have initiated formal collaboration with the Ministry of Health and the Addis Ababa Regional Health Bureau to pilot the NALS service in health centers and non-referral hospitals in Addis Ababa.

A key strength of this study was the large number of neonates delivered at SPHMMC, which allowed for the inclusion of large
TABLE 6 | Quotes regarding the impact made by the Advanced Life Support (ALS) Team at St. Paul's Hospital.

Major Themes with Representative Quotes from Non-NALS Neonatal Care Providers

\section{Praise for program outcomes}

"The ALS team manages our resuscitations. They are the ones who resuscitate on the way up to here. They have received special training about resuscitating. We have seen a big difference because of them. More babies are surviving initially and later on." -Neonatal Nurse

"There is a new program in place for resuscitation. They have trained some special nurses, I think ones that used to be in the NICU, to be the managers of resuscitating babies. From what I hear and what I have seen, they do a good job, especially when you consider the need to keep babies warm and manage birth asphyxia, which is a real problem here." - Pediatric Resident

"The ALS team is doing well; they are doing good with respect to managing hypothermia. Usually, the hypothermia upon arrival is present if they are admitted from outside. Usually these babies were arriving with hypothermia. But in those that have delivered in St. Paul, the hypothermia rate is low. It is a lot less common now because of the attention paid at delivery." - Pediatric Resident

\section{Improvement in workflow}

"The ALS nurses are also deciding if the baby needs to come to the NICU by assessing the condition after birth. For these deliveries, survival is better. Also, workload is better in the NICU because the ALS team has already resuscitated most of the time." - Neonatal Fellow

\section{Desire for additional training opportunities}

"To help the newborn survival rate we have a new program called 'Advanced Life Support' for the newborns. These nurses have significantly decreased the number of admissions to the NICU. And we have seen a significant drop in early newborn deaths in the labor ward. They provide immediate and dedicated care to the newborn, and the outcomes have been impressive. So, whatever we did with the nurses, the resuscitation training in the labor ward, we have to replicate it in the NICU." - Senior Hospital Official Executive

"The ALS nurses are trained on resuscitation, but the nurses in the NICU need similar training. With the ALS nurses we have seen significant improvement in early neonatal deaths and on the number of babies being admitted for NICU, especially attributed to birth asphyxia.

"These outcomes are due to training, and retraining. Success comes from obtaining skills, but also, those skills need to be maintained." - Senior Pediatrician

Quotes were obtained during qualitative interviews of neonatal nurses and physicians in January 2018.

cohort sizes with relatively stable demographics. The only change associated with a clinical practice that occurred during the study period was the introduction of the NALS service. Furthermore, a group of 11 initial NALS providers began training together and remained in their positions throughout the study period and six more NALS providers from the second cohort joined the team in September 2018. The NALS providers were present as a supplement to the standard staffing protocol in LDU. Additionally, data were captured in real-time, electronically entered, and verified by a third party. Finally, the semi-structured interviews used in the qualitative analysis were carried out by researchers not involved in the design or education of the NALS team; thus, a bias that could have been introduced by the interviewer or interviewees was avoided.

We encountered several challenges that have been welldescribed in previous studies addressing the implementation of 
neonatal resuscitation education in LMICs (27-30). Resistance to change was vocalized by nurses and midwives working in the delivery room who were concerned about the loss of relevance and job security. Staff concerns were addressed through a series of group meetings during which outcome data were presented, discussed, and used to support the rationale and intent of implementing this new clinical service. Process issues, including a lack of functioning basic equipment and availability of consumable products, were noted. This issue was initially managed using supplies for clinical service and instruction that were donated by Wax and Gold; ultimately, SPHMMC's Central Supply and Purchasing Department was able to identify and secure the necessary equipment and inventory.

Limitations of our study include incomplete data on demographic characteristics of the newborns both in the preimplementation period and in groups B and C, causes of death were not recorded, and temperatures in newborns within the first $h$ of life were not recorded before the NALS service rollout. Although no other QI projects were on going in the LDU during the NALS service implementation period, further research is necessary to identify if there was a direct correlation between the improved outcome indicators and the implementation of the NALS service. With respect to the qualitative analysis, the use of an interpreter in certain interviews is a notable limitation of this study because some nuances may have been lost; however, allowing respondents to communicate in their language might also have led to the obtainment of responses that were more thorough than the responses that would be obtained if their native language had not been used. Lastly, as with any interview-based project, there is a possibility of responses being biased due to a desire to avoid presenting a negative opinion of the program to a visiting physician.

\section{CONCLUSION}

Our study demonstrates the efficacy and acceptability of LDHF training to implement a NALS service at a tertiary care hospital in Ethiopia. Through the partnership, capacity-building, and focused quality-improvement methods, the implementation of the NALS program led to significant and sustained improvements in the neonatal resuscitation and management skills of delivery

\section{REFERENCES}

1. World Health Organization: WHO. Newborns: Reducing Mortality. Who.int. Published September 19. (2019). Available online at: https://www.who.int/news-room/fact-sheets/detail/newbornsreducingmortality (accessed September 2, 2021).

2. Neonatal mortality - UNICEF DATA. UNICEF Data. (2018). Available online at: https://data.unicef.org/topic/child-survival/neonatal-mortality/ (accessed September 4, 2021).

3. Usman F, Imam A, Farouk ZL, Dayyabu AL. Newborn mortality in subsaharan africa: why is perinatal asphyxia still a major cause? Ann Glob Health. (2019) 85:112. doi: 10.5334/aogh.2541

4. Ethiopia: Mini Demographic and Health Survey. (2019). Available online at: https://dhsprogram.com/publications/publication-FR363-DHS- FinalReports.cfm (accessed September 1, 2021). room attendants. This may have contributed to the reduction in the observed neonatal mortality and morbidity. Additionally, the qualitative analysis revealed the key stakeholders' buyin and support of the NALS program. With respect to the goal of improving neonatal outcomes in LMIC with the highest neonatal mortality and morbidity rates, continued collaboration with local providers and key administrative and government stakeholders are vital to the development, implementation, and scale-up of educational programs for neonatal-resuscitation providers.

\section{DATA AVAILABILITY STATEMENT}

The raw data supporting the conclusions of this article will be made available by the authors, without undue reservation.

\section{ETHICS STATEMENT}

The studies involving human participants were reviewed and approved by Institutional Review Board (IRB) of St. Paul's Hospital Millennium Medical College. Written informed consent for participation was not required for this study in accordance with the national legislation and the institutional requirements.

\section{AUTHOR CONTRIBUTIONS}

LP, MT, PP, SH, SR, SK, TE, and WG conceptualized and designed the study. MT, PP, SH, TE, and TK collected the data, while MT and SR analyzed the data. LP, MT, and SH drafted the initial manuscript. All authors contributed to the article and approved the submitted version.

\section{ACKNOWLEDGMENTS}

This work would not have been possible without the tireless dedication of the members of the Neonatal Advanced Life Support team, the generous contribution of Wax and Gold volunteers, donation of educational materials by the S.T.A.B.L.E program, and the commitment of the administrative leadership at SPHMMC. We would also like to extend our gratitude to Dr. Brett Nelson and Dr. Julia Johnson for their feedback on the content and revision of the manuscript.

5. Demisse AG, Alemu F, Gizaw MA, Tigabu Z. Patterns of admission and factors associated with neonatal mortality among neonates admitted to the neonatal intensive care unit of university of gondar hospital, northwest Ethiopia. Pediatr Health Med Ther. (2017) 8:57-64. doi: 10.2147/PHMT.S1 30309

6. Hadgu FB, Gebretsadik LG, Mihretu HG, Berhe AH. Prevalence and factors associated with neonatal mortality at ayder comprehensive specialized hospital, northern Ethiopia. A cross-sectional study. Pediatr Health Med Ther. (2020) 11:29-37. doi: 10.2147/PHMT.S235591

7. Tewabe T, Mehariw Y, Negatie E, Yibeltal B. Neonatal mortality in the case of felege hiwot referral hospital, bahir dar, amhara regional state, north west Ethiopia 2016: a one-year retrospective chart review. Ital J Pediatr. (2018) 44:57. doi: 10.1186/s13052-018-0498-5

8. Ethiopia: Health Newborn Network. (2017). Available online at: https://www. healthynewbornnetwork.org/country/ethiopia/ (accessed September 1, 2021). 
9. Gobezie WA, Bailey P, Keyes E, Ruano AL, Teklie H. Readiness to treat and factors associated with survival of newborns with breathing difficulties in Ethiopia. BMC Health Serv Res. (2019) 19:552. doi: 10.1186/s12913-019-4390-9

10. Desalew A, Sintayehu Y, Teferi N, Amare F, Geda B, Worku T, et al. Cause and predictors of neonatal mortality among neonates admitted to neonatal intensive care units of public hospitals in eastern ethiopia: a facility-based prospective follow-up study. BMC Pediatr. (2020) 20:160. doi: 10.1186/s12887-020-02051-7

11. Sintayehu Y, Desalew A, Geda B, Tiruye G, Mezmur H, Shiferaw K, et al. Basic neonatal resuscitation skills of midwives and nurses in eastern ethiopia are not well retained: an observational study. PLoS ONE. (2020) 15:e0236194. doi: 10.1371/journal.pone.0236194

12. Abrha MW, Asresu TT, Araya AA, Weldearegay HG. Healthcare professionals' knowledge of neonatal resuscitation in ethiopia: analysis from 2016 national emergency obstetric and newborn care survey. Int $J$ Pediatr. (2019) 2019:8571351. doi: 10.1155/2019/85 71351

13. Kamath-Rayne BD, Berkelhamer SK, Kc A, Ersdal HL, Niermeyer S. Neonatal resuscitation in global health settings: an examination of the past to prepare for the future. Pediatr Res. (2017) 82:194-200. doi: 10.1038/pr.2017.48

14. Enweronu-Laryea C, Dickson KE, Moxon SG, Simen-Kapeu A, Nyange C, Niermeyer SV, et al. Basic newborn care and neonatal resuscitation: a multicountry analysis of health system bottlenecks and potential solutions. BMC Pregnancy Childbirth. (2015) 15:S4. doi: 10.1186/1471-2393-15-S2-S4

15. Wall SN, Lee ACC, Carlo W, Goldenberg R, Niermeyer S, Darmstadt GL, et al. Reducing intrapartum-related neonatal deaths in low- and middle-income countries-what works? Semin Perinatol. (2010) 34:395407. doi: 10.1053/j.semperi.2010.09.009

16. Haile-Mariam A, Tesfaye N, Otterness C, Bailey PE. Assessing the health system's capacity to conduct neonatal resuscitation in Ethiopia. Ethiop Medical J. (2012) 50:43-55.

17. Ersdal HL, Vossius C, Bayo E, Mduma E, Perlman J, Lippert A, et al. A one-day "helping babies breathe" course improves simulated performance but not clinical management of neonates. Resuscitation. (2013) 84:14227. doi: 10.1016/j.resuscitation.2013.04.005

18. Orfaly RA, Frances JC, Campbell P, Whittemore B, Joly B, Koh H. Train-theTrainer as an educational model in public health preparedness. J Public Health Manag Pract. (2005) S123-7. doi: 10.1097/00124784-200511001-00021

19. Jhpiego Resource Brief. Low Dose, High Frequency: A Learning Approach to Improve Health Workforce Competence, Confidence, and Performance. (2016). Available online at: https://www.healthynewbornnetwork.org/hnn-content/ uploads/Jhpiego-LDHF_briefer-1.pdf (accessed October 18, 2021).

20. Helping Babies Survive (2015). Available online at: https://www.aap.org/enus/advocacy-and-policy/aaphealth-initiatives/helping-babies-survive/Pages/ default.aspx (n.d.) (accessed September 7, 2021).

21. Weiner GM, Zaichkin J, Kattwinkel J. Textbook of Neonatal Resuscitation. Elk Grove Village, IL: American Academy of Pediatrics (2016).

22. Karlsen K. The S.T.A.B.L.E. Program Pre-Transport Post-Resuscitation Stabilization Care of Sick Infants: Guidelines for Neonatal Healthcare Providers: Instructor Manual. Park City, UT: STAB.L.E (2013).
23. Neonatal Orientation and Education Program. 4th ed. Available online at: https://www.awhonn.org/page/NOEP3 (n.d.). (accessed September 7, 2021).

24. XАMPP for Windows version 3.2.2. (2011). Available online at: https://www. apachefriends.org/download.html (n.d.) (accessed May 4, 2017).

25. Asegid A, Belachew T, Yimam E. Factors influencing job satisfaction and anticipated turnover among nurses in sidama zone public health facilities, south Ethiopia. Nurs Res Pract. (2014) 2014:909768. doi: 10.1155/2014/909768

26. Semachew A, Belachew T, Tesfaye T, Adinew YM. Predictors of job satisfaction among nurses working in Ethiopian public hospitals, 2014: institution-based cross-sectional study. Hum Resour Health. (2017) 15:31. doi: 10.1186/s12960-017-0204-5

27. Rule ARL, Tabangin M, Cheruiyot D, Mueri P, Kamath-Rayne BD. The call and the challenge of pediatric resuscitation and simulation research in low-resource settings. Simul Healthc. (2017) 12:402-6. doi: 10.1097/SIH.0000000000000260

28. Kc A, Ewald U, Basnet O, Gurung A, Pyakuryal SN, Jha BK, et al. Effect of a scaled-up neonatal resuscitation quality improvement package on intrapartum-related mortality in nepal: a steppedwedge cluster randomized controlled trial. PLoS Med. (2019) 16:e1002900. doi: 10.1371/journal.pmed.1002900

29. Opiyo N, Were F, Govedi F, Fegan G, Wasunna A, English M. Effect of newborn resuscitation training on health worker practices in pumwani hospital, Kenya. PLoS ONE. (2008) 3:e1599. doi: 10.1371/journal.pone.0001599

30. Bellad RM, Bang A, Carlo WA, McClure EM, Meleth S, Goco N, et al. A prepost study of a multi-country scale up of resuscitation training of facility birth attendants: does helping babies breathe training save lives? BMC Pregnancy Childbirth. (2016) 16:222. doi: 10.1186/s12884-016-0997-6

Conflict of Interest: The authors declare that the research was conducted in the absence of any commercial or financial relationships that could be construed as potential conflicts of interest.

Wax and Gold, Inc. is a 501(c)3 non-profit volunteer-based organization working in Ethiopia in education and capacity building to improve newborn healthcare. It has no paid staff, and all its members and founders are volunteers.

Publisher's Note: All claims expressed in this article are solely those of the authors and do not necessarily represent those of their affiliated organizations, or those of the publisher, the editors and the reviewers. Any product that may be evaluated in this article, or claim that may be made by its manufacturer, is not guaranteed or endorsed by the publisher.

Copyright (c) 2021 Tadesse, Hally, Rent, Platt, Eusterbrock, Gezahegn, Kifle, Kukora and Pollack. This is an open-access article distributed under the terms of the Creative Commons Attribution License (CC BY). The use, distribution or reproduction in other forums is permitted, provided the original author(s) and the copyright owner(s) are credited and that the original publication in this journal is cited, in accordance with accepted academic practice. No use, distribution or reproduction is permitted which does not comply with these terms. 